\title{
KETAMINE AS A NOVEL DRUG FOR DEPRESSION TREATMENT
}

\author{
Bartosz Kaczmarek ${ }^{1}$, Krzysztof Kowalski ${ }^{2}$, Bogna Bogudzińska ${ }^{3}$ \& Patryk Piotrowski ${ }^{4}$ \\ ${ }^{1}$ Graduate of the Medical University of Lodz, Rotational Trainee in University Teaching Hospital \\ in Wroclaw, Psychiatry Student Research Club, Poland \\ ${ }^{2}$ Psychiatry Student Research Club, Wroclaw Medical University, Poland \\ ${ }^{3}$ Psychiatry Student Research Club, Wroclaw Medical University, Poland \\ ${ }^{4}$ Department and Clinic of Psychiatry, Wroclaw Medical University, Section of Epidemiology and Social Psychiatry, \\ Wroclaw, Poland
}

received: 25.5.2021;

revised: 6.7.2021;

accepted: 16.8 .2021

\section{SUMMARY}

Background: Depression is one of the most common mental disorders. Currently used antidepressants, acting on the monoaminergic system, are insufficient for depression treatment. In recent years, potential application of NMDA receptor modulators in the treatment of drug-resistant depression has gained attention. Administration of ketamine, being a non-competitive NMDA receptor antagonist, contributes to a faster remission of symptoms.

Subjects and methods: The aim of this paper is to review current studies on the use of ketamine in the treatment of drug-resistant depression, compare results of various administration methods - intravenous, intranasal or oral, as well as compare its effectiveness with that of other antidepressants.

Results: Numerous studies show the drug is effective and well tolerated, particularly in patients with increased suicidal thoughts. However, there are concerns on increasing tolerance to the drug and the possibility of implementing a long-term treatment.

Conclusion: Oral and intranasal forms of the drug are particularly promising due to their non-invasiveness and ability to selfadminister. In March 2019, S-ketamine nasal spray was registered by the FDA for the treatment of drug-resistant depression.

Key words: depression - ketamine - NMDA receptor

\section{INTRODUCTION}

Unipolar depressive disorder is the most frequent mental disorder. Currently, depression is the second contributor of global disability (Ferrari et al. 2013). According to statistics, $30 \%$ of patients suffering from unipolar disorder meet drug resistance criteria (Little 2009). The pathophysiology of depression is still largely unknown. Most likely, impaired function of the monoaminergic system in the central nervous system is the main contributing factor. Currently used antidepressants, acting on the monoaminergic system, are characterised by a delayed effect (Mathew et al. 2012). The disease manifests itself with the Beck's triad, which includes anergia, anhedonia and sadness (Beck 1963). Depression is considered treatment-resistant if the patient is unresponsive after being administered at least two adequate and long enough courses of various antidepressants (Voineskos et al. 2020).

Ketamine, a phencyclidine derivative, is a hallucinogen commonly used for general anaesthesia (Muller et al. 2016). In treatment-resistant depression, glutamate neurotransmission is impaired (Sanacora et al. 2012). Besides, people affected by this disease demonstrate elevated levels of blood glutamic acid (Altamura et al. 1995). Additionally, severity of unipolar depressive disorder correlates with blood glutamate concentration. The ketamine mechanism of action is associated with noncompetitive NMDA (N-methyl-D-aspartate) antagonism, located especially on GABA (gamma-aminobutyric acid) interneurons. It results in an increased level of glutamic concentration in the synaptic cleft. Then glutamate binds AMPA (alpha-amino-3-hydroxy-5-methyl-4isoxazolepropionic acid) receptors. Finally, BDNF (brain derived neurotropic factor) signal is amplified in mTORC1 (mechanistis target of rapamycin complex 1) pathway, which results in augmentation of synaptic plasticity and neurogenesis (Matveychuk et al. 2020). The complex mechanism of action of ketamine explains why other NMDA antagonists (eg. memantine, lanicemine and nitrous oxide) do not have an antidepressant effect (Newport et al. 2015). What is more, such antidepressant effect of ketamine does not occur in genetic mice lacking the BDNF gene (Autry et al. 2011).

Neuroimaging studies performed with the use of the by fMRI technique allowed to measure ketamine potential. It turned out that drug infusions had a different, often opposite, effect on people in an episode of major depression than in healthy controls. Ketamine normalised the activity in brain centers, responsible for the regulation of emotions, such as amygdala or parahippocampal gyrus in sick patients (Reed et al. 2018). The neuroplastic role of ketamine, i.e. reversal of prefrontal cortex neural atrophy, which is characteristic of depression, has also been proven (Ly et al. 2018).

Ketamine is a racemate composed of two enantiomers - $\mathrm{R}(-)$ and $\mathrm{S}(+)$. They differ in rotation of polarised light; enantiomer $\mathrm{S}$ rotates to the left whereas $\mathrm{R}$ - to the 
right. The following aspects should be taken into account while applying the ketamine racemic form (Baker et al. 2002):

- therapeutic and side effects of the particular enantiomers;

- differences in absorption, excretion and protein binding between the enantiomers;

- preferential metabolism of one enantiomer over the other by enzymes;

- difference in interacting with other drugs;

- influence on mutual pharmacokinetics.

$\mathrm{S}(+)$ ketamine has better affinity to the NMDA receptor and demonstrates a stronger analgesic effect than $\mathrm{R}(-)$ ketamine and racemate (Mihaljević et al. 2020). On the other hand, R(-) ketamine has a faster antidepressant effect and less side effects than $\mathrm{S}(+)$ ketamine (Yang et al. 2019). R(-) ketamine also improves phencyclidine-induced cognitive deficits. $\mathrm{S}(+)$ ketamine is deprived of that action (Tan et al. 2020). In addition, $\mathrm{S}(+)$ ketamine has more rapid metabolism and consequent recovery. $\mathrm{S}(+)$ ketamine also causes less emergence delirium compared to racemic form (White et al. 1980, Kienbaum et al. 2001). CYP2B6, CYP2C9 and CYP3A4 metabolise ketamine to norketamine by $\mathrm{N}$-demethylation process and $\mathrm{S}(+)$ norketamine has less side effects than $\mathrm{S}(+)$ ketamine (Hashimoto et al. 2019). In therapeutic doses, $\mathrm{S}(+)$ and $\mathrm{R}(-)$ ketamines are metabolised by CYP2B6 (Yanagihara et al. 2001). Bioavailability of ketamine depends on the route of administration and are as follows (Li et al. 2016, Peltoniemi et al. 2016):

- intravenous (100\%);

- intranasal (45\%);

- sublingual (30\%);

- oral (20\%);

- intramuscular (93\%);

- rectal (30\%).

Additionally, ketamine can also be administered by subcutaneous route (Mion 2017).

$\mathrm{S}(+)$ ketamine administered in controlled trials for a period of above 1 year appeared to be safe (Swainson et al. 2019). However, like other substances, also ketamine has side effects. It might cause (Andrade 2019):

- increased blood pressure;

- dizziness;

- nausea and vomiting;

- drowsiness;

- perceptual disturbance;

- dissociation.

Ketamine also has addictive properties. The probability of the above mentioned side effects rises when applied doses are higher than recommended (Jhang et al. 2015).
This paper aims to review previous studies on the use of ketamine in the treatment of major depressive disorder, to compare results of various ways of its application: intravenous, intranasal and oral, and finally, to compare its effectiveness with that of other current antidepressant therapies.

\section{LITERATURE REVIEW}

\section{Research on intravenous ketamine administration in patients with suicidal ideation}

Currently, more and more people suffer from suicidal ideation. Suicide is one of three major causes of worldwide mortality in individuals, aged 15-44 (Aleman et al. 2014). Over $90 \%$ of patients with suicidal ideation report mood disturbances as the primary cause (Cavanagh et al. 2003). Wilkinson used the below scales to evaluate the probability of attempting suicide:

- Montgomery-Åsberg Depression Rating Scale (MADRS);

- Hamilton Depression Rating Scale (HAM-D);

- Quick Inventory of Depressive SymptomatologySelf Report (QIDS-SR) (Figure 1);

- Beck Depression Inventory (BDI).

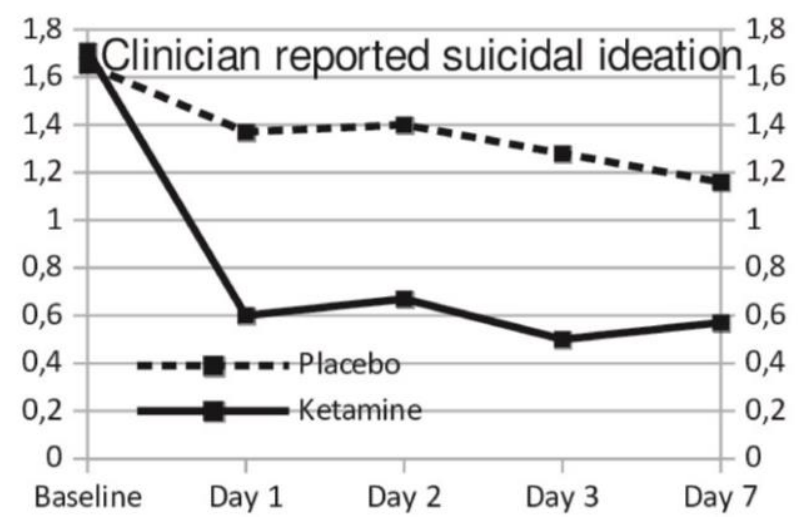

Figure 1. Reduction in depressive symptoms in the QIDS-SR scale after intravenous ketamine/placebo administration (Wilkinson et al. 2018)

Results of studies indicate that antidepressive effects of a single intravenous dose of ketamine are observed as early as after a day. $89.2 \%$ of subjects report significant reduction in suicidal ideation, observed for at least one week after ketamine administration compared to $42.9 \%$ of the controls, who were administered $0.9 \% \mathrm{NaCl}$ or midazolam. Clinicians report improvement in $86 \%$ of subjects in the ketamine group compared to $52.9 \%$ of subjects in the control group. Ketamine has a great antidepressant potential and the improvement is observed for at least one week following a single infusion (Wilkinson et al. 2018).

Reduced suicidal ideation, induced by intravenous administration of ketamine, is noted already within 40 minutes after the infusion (Ballard et al. 2014), whereas SSRIs (selective serotonin reuptake inhibitors) induce 
such antidepressant effects as late as after two weeks (Ting et al. 2012). Besides, SSRIs applied in patients suffering from bipolar affective disorder could worsen their mood and contribute to more frequent episodes of suicidal ideation (Hennen et al. 2005).

Additionally, fewer episodes of suicidal ideation are observed only in adults (not in adolescents) (Gibbons et al. 2012).

Also anxiety disorders increase the probability of suicidal behaviour (Goldberg et al. 2012). In research published by Ballard, which shows a correlation between feeling of anxiety and suicidal ideation and between depression occurrence and suicidal ideation, the following scales were used:

- HAM-D, which takes into account psychic anxiety, somatic anxiety, general somatic symptoms, gastrointestinal symptoms, hypochondriasis, and insight ;

- Scale for Suicide Ideation (SSI) used to determine the wish to live (Figure 2) and the wish to die (Figure 3).

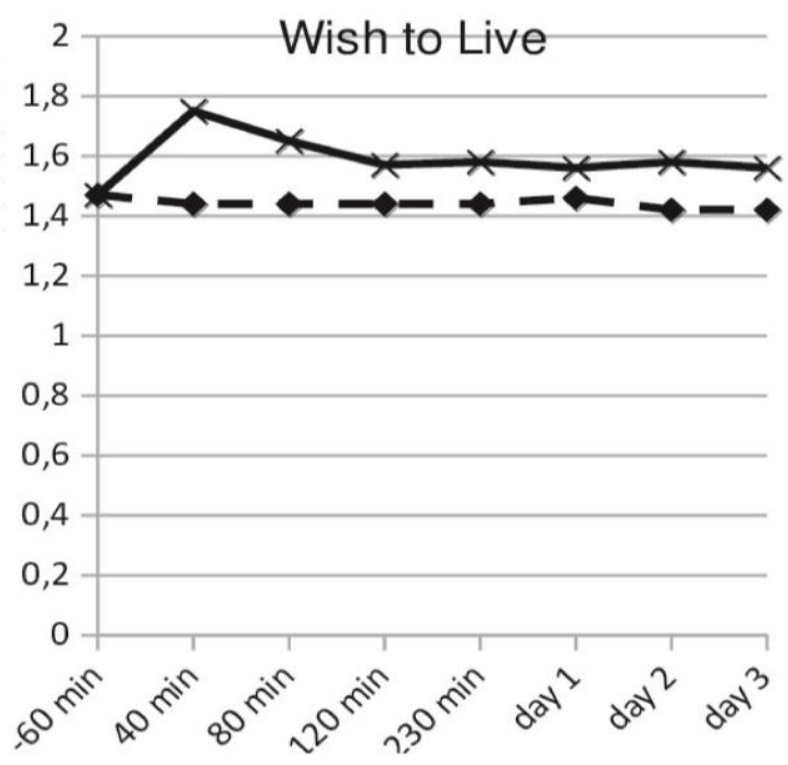

Figure 2. Wish to live in SSI after intravenous ketamine administration at a dose of $0.5 \mathrm{mg} / \mathrm{kg}$ (the solid line) vs placebo (the dotted line)

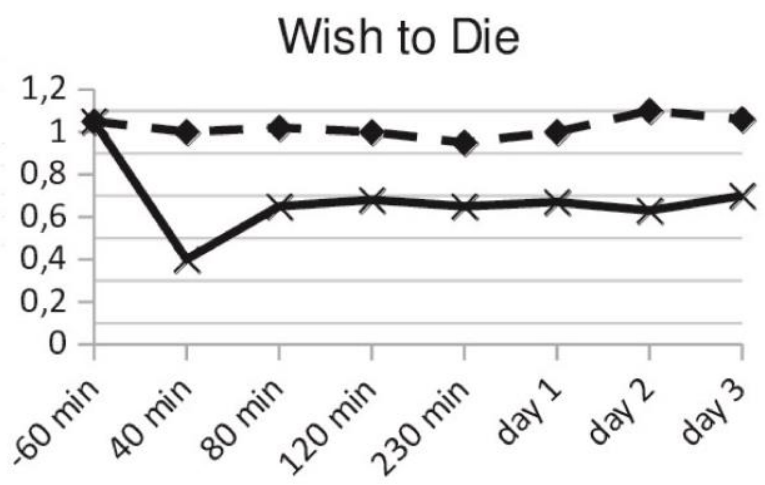

Figure 3. Wish to die in SSI after intravenous ketamine administration at a dose of $0.5 \mathrm{mg} / \mathrm{kg}$ (the solid line) vs placebo (the dotted line)
Studies show that a single intravenous ketamine administration at a dose of $0.5 \mathrm{mg} / \mathrm{kg}$ results in a significant reduction of suicidal ideation, which is related to, but also independent of reductions in depression and anxiety. Additionally, a single dose of intravenous ketamine increases the wish to live and suppresses the wish to die. An antisuicidal effect is the strongest after 40 minutes of administration. However, side effects are also most pronounced within 40 minutes after administration of the drug (Ballard et al. 2014). Reductions in suicidal ideation following ketamine infusion are related to, but also independent of, reductions in depression and anxiety. As interventions for suicidal ideation are critically needed in psychiatry, findings suggest that evaluations of ketamine can be used to further investigate the neurobiology and best treatments for suicidal individuals (Jakuszkowiak-Wojten et al. 2019).

Intravenous ketamine administration significantly reduces depressive symptoms in unipolar and bipolar affective disorders. However, a better antidepressant effect was observed in patients with unipolar affective disorder (McGirr et al. 2015) in whom remission lasted at least 7 days (Kishimoto et al. 2016), compared to 3-4 day-remission, noted in patients with bipolar affective disorder (Romeo et al. 2015).

\section{Intranasal administration of ketamine}

Intranasal medications are exceptionally rarely administered in modern psychiatry. This administration method, however, is highly beneficial. Absorption through the nasal epithelium allows to avoid the first-pass effect and cross the blood-brain barrier. The blood level of intranasally administered ketamine increases rapidly and achieves a therapeutic effect (Henkin 2011).

In one of the first intranasal ketamine studies, conducted by Lapidus, a 50-mg dose of $\mathrm{S}(+)$ ketamine was administered to the study group. An improvement was observed as early as after 40 minutes following the administration and it stayed for 7 days after a single dose (Lapidus et al. 2014). However, it was slightly weaker than the dose of $0.5 \mathrm{mg} / \mathrm{kg}$ b.w. administered intravenously, which was associated with lower blood levels of the drug for the comparable intranasal dose. In phase II of the trial, a 84-mg dose appeared to be more effective than a 56-mg dose and the treatment effect was maintained for 2 months in a follow-up study, preceded by additional open-label maintenance treatment with 28 $\mathrm{mg}$ doses. The average sustained decrease in the score of the MADRS scale was high, i.e.11.6 points. These results are comparable to the dose of $0.2 \mathrm{mg} / \mathrm{kg} \mathrm{b}$.w. of intravenously administered $\mathrm{S}(+)$ ketamine (Daly et al. 2018). However, phase III study on intranasal $\mathrm{S}(+)$ ketamine administration, conducted by Fedgchin, showed a statistically significant clinical improvement of the score of the MADRS scale for a 56-mg dose given twice a week for 4 weeks in comparison to the application of a different antidepressant and placebo inhalation. On the other hand, the study did not confirm a 
beneficial effect for a 84-mg dose, which was related to methodological limitations of the study (Fedgchin et al. 2019). In other publications, dissociative and psychotomimetic side effects as well as haemodynamic changes were less frequent and less severe than for intravenous administration of the drug. It should be emphasised that the above-mentioned studies were double-blind, randomised and accompanied by a simultaneous treatment with a new oral antidepressant that affects the biogenic amine system, due to a clinically dangerous condition of patients in drug-resistant major depression and related ethical aspects. The largest number of participants included in this type studies has been only 346 so far. Thus, it will be necessary to carry out studies on larger groups in the future. This will allow for systematisation of treatment regimens.

It is also worth pointing out preliminary reports from phase II clinical trials, conducted on patients suffering from drug-resistant depression in the course of bipolar disorder. The trials appeared to be significantly beneficial. The difference in the MADRS score after discontinuation of placebo was: on day 145.9 for a 24 $\mathrm{mg}$ dose, 6.7 for a $36-\mathrm{mg}$ dose and 8.2 for a $48-\mathrm{mg}$ dose (Celon Pharma 2021).

$\mathrm{S}(+)$ ketamine has been approved by the FDA for the treatment of drug resistant depression since 2019. Its distribution is limited by the REMS (Risk Evaluation and Mitigation Strategy) protocol due to a potential risk of misusing the specimen. A patient, having been administered the drug, has to be monitored by a health care provider for 2 hours after the application of the drug. The patient is disallowed to take the drug home and drive any vehicles on that day (Food \& Drug Administration 2019). According to the treatment schedule, the drug should be applied at doses of 56 or $84 \mathrm{mg}$ (and $28 \mathrm{mg}$ for people above 65 years of age). The drug should be administered twice per week during the 2-week induction phase; then, once a week for at least 4 weeks or longer, depending on the patient's clinical condition.

Psychiatrists should pay special attention to commonly used drugs, such as sildenafil or tricyclic antidepressants which increase the congestion of the mucosa. They can cause nasal obstruction, reported by patients as runny or stuffy nose, and in consequence, significantly reduce the bioavailability of the drug (Kiroglu et al. 2006). On the other hand, vasoconstrictor drugs and inhaled glucocorticosteroids should not be used up to an hour before an inhalation. Moreover, it is worth noting that ketamine has got indirect sympathomimetic properties. It stimulates release of noradrenaline which leads to increased blood pressure, heart rate, cardiac output and consequently to increased myocardial oxygen consumption (Kurdi et al. 2014). Due to this fact there are contraindications to use of the drug: aneurysms, a history of intracerebral haemorrhage and other intracranial pathologies which lead to increased intracranial pressure (Janssen 2021).
Besides, severe coronary artery disease or recent (up to 6 weeks) cardiovascular events are also contradictions to ketamine use (Rathmell \& Rosow 2015).

\section{Oral administration of ketamine}

Oral administration of ketamine is characterised by low bioavailability. The rate of absorption of the drug depends on genetic factors, food ingestion, variable intestinal motility and gastric condition. In addition, it undergoes intensive first-pass metabolism in the liver. Due to this fact, only $17-23 \%$ of the drug dose reaches the circulatory system (Smith-Apeldoom et al. 2019).

One of the first reports of a clinical case series on the effectiveness and tolerance of the oral form of the drug was presented in Pharmacopsychiatry. Patients were treated simultaneously for 14 days with ketamine and antidepressants. Two of them received venlafaxine at a dose of $150 \mathrm{mg} / \mathrm{d}$, the third participant received venlafaxine and trimipramine at doses of $225 \mathrm{mg} / \mathrm{d}$ and $100 \mathrm{mg} / \mathrm{d}$, respectively. The fourth participant received duloxetine at a dose of $60 \mathrm{mg} / \mathrm{d}$. Only two patients with melancholic features responded to the treatment The other patients were unresponsive (Paslakis et al. 2010). Another study conducted by Arabzadeh on a group of 81 individuals revealed that ketamine can act as an adjuvant for sertraline.

There was a statistically significant improvement in the HRDS score after 2 weeks of application of oral ketamine administered at a dose of $25 \mathrm{mg} / \mathrm{d}$ twice daily in combination with sertraline, administered at a dose of $150 \mathrm{mg}$ daily in comparison with patients receiving sertraline and placebo. In addition, the frequency of adverse effects did not differ between the two groups. The effect maintained for 6 weeks after the initiation of the therapy (Arabzadeh et al. 2018).

During a 28-day study published by Irwin, ketamine was administered orally at a dose of $0.5 \mathrm{mg} / \mathrm{kg}$ to hospice patients. The product was shown to cause remission of depressive symptoms on the HADS scale after 14 days, and anxiety symptoms after 3 days following its introduction. The improvement was maintained for 28 days after the drug was discontinued (Irwin et al. 2013). In a double-blind, randomised study, conducted by Domany, subjects received ketamine orally at a dose of $1 \mathrm{mg} / \mathrm{kg} 3 \mathrm{x}$ weekly or placebo for 21 days. On the last day of the study, the mean MARDS score decrease for the ketamine group was 12.75 points, compared to placebo subjects, for whom the value was 2.49 points. Besides, ketamine was well tolerated. Dizziness and euphoria were reported by 4 patients; other side effects were slight and occurred as frequently as in the placebo group.

An additional patient assessment was made 7 days after the completion of study. It showed that there was no increase in depressive symptoms, and the mean MARDS score was still lower than the baseline (Domany et al. 2018). 
Oral administration of ketamine allows for higher serum concentrations of norketamine, which contributes to analgesic effects of this drug (Lapidus et al. 2014). A 6-week study, conducted by Jafarinia, confirmed the efficacy of the oral form of ketamine in remission of depressive symptoms in patients with chronic pain.

The mean HADS score was lower in patients taking ketamine at a dose of $150 \mathrm{mg} /$ day compared to the group receiving diclofenac at the same dose after just one week of application. However, no statistically significant differences were observed regarding the pain level on the VAS rating scale (Jafarinia et al. 2016).

The oral form of drug could become an alternative to the intravenous one due to less invasive administration, good tolerance, and the possibility of selfadministration (Arabzadeh et al. 2018). Furthermore, the oral form of ketamine is less addictive than the intranasal form. A study conducted by Hartberg provides further evidence for good tolerance of this drug. The most common adverse reactions experienced by patients after its administration were headache, sedation, blood pressure fluctuations, and vomiting. However, they were of short-lasting and did not require a medical intervention (Hartberg et al. 2018).

Oral administration of ketamine would be a simpler and cheaper form of treatment, especially in countries enjoying a high standard medical care (Andrade 2019). Development of safe and effective home treatment regimens would promote this route of drug administration (Shirawi et al. 2017). However, the authors of the studies point out a need to conduct further studies on dose ranges and pharmacokinetic interactions with other drugs on a larger number of patients.

\section{CONCLUSIONS}

In the above studies, ketamine appears to be a promising, fast-acting antidepressant, especially in intensified suicidal tendencies. Due to its non-invasive nature, alternative forms of its administration, such as intranasal and oral, seem to be particularly promising. Undoubtedly, a relatively short period of symptom remission is a disadvantage of the drug. Long-term studies are needed in the future to verify the issues of increasing tolerance to the drug and check whether it is possible to effectively maintain treatment effect in the long run and to develop detailed treatment algorithm. It is also necessary to investigate which standard antidepressants may potentially enhance ketamine treatment. Unfortunately, distribution of the preparation may also be problematic in the future as the drug may be potentially addictive and used for recreational purposes and also due to high costs of the ketamine therapy. Ketamine may considerably trigger future development of drugs modulating glutamatergic transmission.
Acknowledgements: None.

Conflict of interest: None to declare.

\section{Contribution of individual authors:}

Bartosz Kaczmarek: aim, part of introduction, review of intravenous ketamine administration, charts.

Krzysztof Kowalski: conclusions, part of introduction, review of intranasal ketamine administration.

Bogna Bogudzińska. review of oral ketamine administration.

Patryk Piotrowski: part of introduction.

\section{References}

1. Arabzadeh S, Hakkikazazi E, Shahmansouri N, et al. Does oral administration of ketamine accelerate response to treatment in major depressive disorder? Results of a double-blind controlled trial. J Affect Disord 2018; 235:236-241

2. Aleman A, Denys D. Mental health: A road map for suicide research and prevention. Nature 2014; 509:421-3

3. Al Shirawi MI, Kennedy SH, Ho KT, Byrne R, Downar J. Oral ketamine in treatment-resistant depression: A clinical effectiveness case series. J Clin Psychopharmacol 2017; 37(4):464-7

4. Altamura C, Maes M, Dai J, Meltzer HY. Plasma concentrations of excitatory amino acids, serine, glycine, taurine and histidine in major depression. Eur Neuropsychopharmacol. 1995; 5 Suppl:71-5

5. Andrade C. Oral ketamine for depression, 1: pharmacological considerations and clinical evidence. J Clin Psychiatry 2019; 80(2). doi:10.4088/JCP.19f12820

6. Andrade C. Oral ketamine for depression, 2: practical considerations. J Clin Psychiatry. 2019; 80. doi:10.4088/JCP.19f12838

7. Autry AE, Adachi M, Nosyreva E, Na ES, Los MF, Cheng $P-F$, et al. NMDA receptor blockade at rest triggers rapid behavioural antidepressant responses. Nature. 2011; 475(7354):91-5

8. Baker AK, Hoffmann VLH, Meert TF. Dextromethorphan and ketamine potentiate the antinociceptive effects of $\mu$ but not $\delta$ - or $\kappa$-opioid agonists in a mouse model of acute pain. Pharmacol Biochem Behav 2002; 74(1):73-86

9. Ballard ED, Ionescu DF, Vande Voort JL, Niciu MJ, Richards EM, Luckenbaugh DA, et al. Improvement in suicidal ideation after ketamine infusion: relationship to reductions in depression and anxiety. $J$ Psychiatr Res. 2014;58:161-6

10. Beck AT. Thinking and depression. I. Idiosyncratic content and cognitive distortions. Arch Gen Psychiatry. 1963; 9:324-33

11. Cavanagh JTO, Carson AJ, Sharpe M, Lawrie SM. Psychological autopsy studies of suicide: a systematic review. Psychol Med. 2003;33(3):395-405

12. Celon Pharma. Positive results of Phase II clinical esketamine DPI Celon Pharma (Falkieri) in drug-resistant bipolar depression. 2021, on: https://celonpharma.com/ pozytywne-wyniki-ii-fazy-klinicznej-esketaminy-dpi-celonpharma-falkieri-w-lekoopornej-depresji-dwubiegunowej/ 
13. Daly EJ, Singh JB, Fedgchin M, Cooper K, Lim P, Shelton $R C$, et al. Efficacy and safety of intranasal esketamine adjunctive to oral antidepressant therapy in treatment-resistant depression: A randomized clinical trial. JAMA Psychiatry 2018; 75:139. doi:10.1001/jamapsychiatry.2017.3739

14. Domany Y, Bleich-Cohen M, Tarrasch R, Meidan R, Litvak-Lazar O, Stoppleman $N$, et al. Repeated oral ketamine for out-patient treatment of resistant depression: randomised, double-blind, placebo-controlled, proof-ofconcept study. Br J Psychiatry 2019; 214(1):20-6

15. Fedgchin M, Trivedi M, Daly EJ, Melkote R, Lane R, Lim $P$, et al. Efficacy and safety of fixed-dose esketamine nasal spray combined with a new oral antidepressant in treatment-resistant depression: Results of a randomized, double-blind, active-controlled study (TRANSFORM-1). Int J Neuropsychopharmacol 2019;22(10):616-30

16. Ferrari AJ, Somerville AJ, Baxter AJ, Norman R, Patten $S B$, Vos $T$, et al. Global variation in the prevalence and incidence of major depressive disorder: a systematic review of the epidemiological literature. Psychol Med 2013; 43:471-81

17. Food \& Drug Administration. FDA approves new nasal spray medication for treatment-resistant depression; available only at a certified doctor's office or clinic, 2019, on: https://www.fda.gov/news-events/press-announcements/ fda-approves-new-nasal-spray-medication-treatmentresistant-depression-available-only-certified

18. Gibbons RD, Brown CH, Hur K, Davis J, Mann JJ. Suicidal thoughts and behavior with antidepressant treatment: reanalysis of the randomized placebo-controlled studies of fluoxetine and venlafaxine: Reanalysis of the randomized placebo-controlled studies of fluoxetine and venlafaxine. Arch Gen Psychiatry 2012; 69:580-7

19. Goldberg D, Fawcett J. The importance of anxiety in both major depression and bipolar disorder: Importance of anxiety in MDD and GAD. Depress Anxiety 2012; 29:471-8

20. Hartberg J, Garrett-Walcott S, De Gioannis A. Impact of oral ketamine augmentation on hospital admissions in treatment-resistant depression and PTSD: a retrospective study. Psychopharmacology. 2018; 235(2):393-8

21. Hashimoto K, Yang C. Is (S)-norketamine an alternative antidepressant for esketamine? Eur Arch Psychiatry Clin Neurosci 2019;269(7):867-8

22. Henkin RI. Intranasal delivery to the brain. Nat Biotechnol 2011; 29(6):480. doi:10.1038/nbt.1866

23. Hennen J, Baldessarini RJ: Suicidal risk during treatment with clozapine: a meta-analysis. Schizophr Res 2005, 73:139-145

24. Irwin SA, Iglewicz A, Nelesen RA, Lo JY, Carr CH, Romero $S D$, et al. Daily oral ketamine for the treatment of depression and anxiety in patients receiving hospice care: a 28-day open-label proof-of-concept trial. J Palliat Med. 2013;16(8):958-65

25. Jafarinia M, Afarideh M, Tafakhori A, Arbabi M, Ghajar $A$, Noorbala AA, et al. Efficacy and safety of oral ketamine versus diclofenac to alleviate mild to moderate depression in chronic pain patients: A double-blind, randomized, controlled trial. J Affect Disord. 2016;204:1-8

26. Janssen Care Path. Spravato, 2021, on https://www.janssencarepath.com/hcp/spravato

27. Jakuszkowiak-Wojten K, Gatuszko-Węgielnik M, Wilkowska A, Stupski J, Włodarczyk A, Górska N, et al. Suicidality in treatment resistant depression: perspective for ketamine use. Psychiatr Danub 2019; 31(Suppl 3):258-60
28. Jhang J-F, Hsu Y-H, Kuо H-C. Possible pathophysiology of ketamine-related cystitis and associated treatment strategies. Int J Urol. 2015;22(9):816-25

29. Kienbaum P, Heuter T, Paviakovic G, Michel MC, Peters $J$ : $S(+)$-ketamine increases muscle sympathetic activity and maintains the neural response to hypotensive challenges in humans. Anesthesiology 2001; 94:252-258

30. Kiroglu AF, Bayrakli H, Yuca K, Cankaya H, Kiris M. Nasal obstruction as a common side-effect of sildenafil citrate. Tohoku J Exp Med. 2006;208(3):251-4

31. Kishimoto T, Chawla JM, Hagi K, Zarate CA, Kane JM, Bauer $M$, et al. Single-dose infusion ketamine and nonketamine $N$-methyl-d-aspartate receptor antagonists for unipolar and bipolar depression: a meta-analysis of efficacy, safety and time trajectories. Psychol Med 2016; 46:1459-72

32. Kurdi MS, Theerth KA, Deva RS: Ketamine: Current applications in anesthesia, pain, and critical care. Anesth Essays Res 2014; 8:283-90

33. Lapidus $K A B$, Levitch $C F$, Perez AM, Brallier JW, Parides MK, Soleimani L, et al. A randomized controlled trial of intranasal ketamine in major depressive disorder. Biol Psychiatry 2014; 76:970-6

34. Li C-T, Chen M-H, Lin W-C, Hong C-J, Yang B-H, Liu R$S$, et al. The effects of low-dose ketamine on the prefrontal cortex and amygdala in treatment-resistant depression: A randomized controlled study: Ketamine Modulates the PFC. Hum Brain Mapp 2016; 37:1080-90

35. Little A. Treatment-resistant depression. Am Fam Physician 2009; 80:167-172

36. Ly C, Greb AC, Cameron LP, Wong JM, Barragan EV, Wilson PC, et al. Psychedelics promote structural and functional neural plasticity. Cell Rep 2018; 23:3170-82

37. Mathew SJ, Shah A, Lapidus K, Clark C, Jarun N, Ostermeyer B, et al. Ketamine for treatment-resistant unipolar depression: current evidence: Current evidence. CNS Drugs 2012;26(3):189-204

38. Matveychuk D, Thomas RK, Swainson J, Khullar A, MacKay M-A, Baker GB, et al. Ketamine as an antidepressant: overview of its mechanisms of action and potential predictive biomarkers. Ther Adv Psychopharmacol 2020; 10:2045125320916657

39. McGirr A, Berlim MT, Bond DJ, Fleck MP, Yatham LN, Lam RW. A systematic review and meta-analysis of randomized, double-blind, placebo-controlled trials of ketamine in the rapid treatment of major depressive episodes. Psychol Med 2015; 45:693-704

40. Mihaljević S, Pavlović M, Reiner K, Ćaćić M. Therapeutic mechanisms of ketamine. Psychiatr Danub 2020; 32:325-33

41. Mion G: History of anaesthesia: The ketamine story - past, present and future. Eur J Anaesthesiol 2017; 34:571-575

42. Muller J, Pentyala S, Dilger J, Pentyala S. Ketamine enantiomers in the rapid and sustained antidepressant effects. Ther Adv Psychopharmacol. 2016; 6:185-92

43. Newport DJ, Carpenter LL, McDonald WM, Potash JB, Tohen M, Nemeroff CB, et al. Ketamine and other NMDA antagonists: Early clinical trials and possible mechanisms in depression. Am J Psychiatry. 2015;172(10):950-66

44. Paslakis G, Gilles M, Meyer-Lindenberg A, Deuschle M. Oral administration of the NMDA receptor antagonist $S$ ketamine as add-on therapy of depression: a case series. Pharmacopsy- chiatr 2010; 43:33-5 
45. Peltoniemi MA, Hagelberg NM, Olkkola KT, Saari TI. Ketamine: A review of clinical pharmacokinetics and pharmacodynamics in anesthesia and pain therapy. Clin Pharmacokinet. 2016; 55(9):1059-77

46. Rathmell JP, Rosow CE: Intravenous Sedatives and Hypnotics. In: Flood P, Rathmell JP, Shafer $S$ (eds): Stoelting's pharmacology and physiology in anesthetic practice. 160-203. Wolters Kluwer Health, 2015

47. Reed JL, Nugent AC, Furey ML, Szczepanik JE, Evans JW, Zarate CA Jr. Ketamine normalizes brain activity during emotionally valenced attentional processing in depression. NeuroImage Clin. 2018;20:92-101

48. Romeo B, Choucha W, Fossati P, Rotge J-Y. Metaanalysis of short-and mid-term efficacy of ketamine in unipolar and bipolar depression. Psychiatry Res 2015; 230(2):682-8

49. Sanacora G, Treccani G, Popoli M. Towards a glutamate hypothesis of depression: an emerging frontier of neuropsychopharmacology for mood disorders. Neuropharmacology. 2012; 62:63-77

50. Smith-Apeldoorn SY, Veraart JKE, Kamphuis J, van Asselt ADI, Touw DJ, Aan Het Rot M, et al. Oral esketamine for treatment-resistant depression: rationale and design of a randomized controlled trial. BMC Psychiatry. 2019; 19:375

51. Swainson J, Thomas RK, Archer S, Chrenek C, MacKay $M-A$, Baker $G$, et al. Esketamine for treatment resistant depression. Expert Rev Neurother 2019; 19:899-911
52. Tan Y, Fujita Y, Qu Y, Chang L, Pu Y, Wang S, et al. Phencyclidine-induced cognitive deficits in mice are ameliorated by subsequent repeated intermittent administration of $(R)$ ketamine, but not (S)-ketamine: Role of BDNF-TrkB signaling. Pharmacol Biochem Behav 2020; 188:172839

53. Ting SA, Sullivan AF, Boudreaux ED, Miller I, Camargo $C A J r$. Trends in US emergency department visits for attempted suicide and self-inflicted injury, 1993-2008. Gen Hosp Psychiatry 2012; 34:557-65

54. Voineskos D, Daskalakis ZJ, Blumberger DM. Management of treatment-resistant depression: Challenges and strategies. Neuropsychiatr Dis Treat 2020; 16:221-34

55. Wilkinson ST, Ballard ED, Bloch MH, Mathew SJ, Murrough JW, Feder A, et al. The effect of a single dose of intravenous ketamine on suicidal ideation: A systematic review and individual participant data meta-analysis. Am J Psychiatry. 2018;175(2):150-8

56. White PF, Ham J, Way WL, Trevor AJ: Pharmacology of ketamine isomers in surgical patients. Anesthesiology. 1980; 52:231-239

57. Yanagihara $Y$, Kariya S, Ohtani M, Uchino K, Aoyama T, Yamamura $Y$, et al. Involvement of CYP2B6 in $n$ demethylation of ketamine in human liver microsomes. Drug Metab Dispos 2001; 29:887-90

58. Yang C, Yang J, Luo A, Hashimoto K. Molecular and cellular mechanisms underlying the antidepressant effects of ketamine enantiomers and its metabolites. Transl Psychiatry 2019; 9:280
Correspondence:

Bartosz Kaczmarek, MD

Graduate of the Medical University of Łódz

F. Marciniaka 16, 63-500 Ostrzeszów, Poland

E-mail: bkaczmarek1995@gmail.com 